\title{
ILCEA
}

Revue de l'Institut des langues et cultures

d'Europe, Amérique, Afrique, Asie et Australie

33 | 2018

Femmes en résistance du XVIIIe siècle à nos jours

\section{Pauline Roland. El compromiso de una vida militante}

Pauline Roland. L'engagement d'une vie militante

Pauline Roland. The Commitment of a Militant Life

\section{Sara Sánchez Calvo}

\section{(2) OpenEdition}

\section{Journals}

Edición electrónica

URL: http://journals.openedition.org/ilcea/5062

DOI: $10.4000 /$ ilcea.5062

ISSN: 2101-0609

Editor

UGA Éditions/Université Grenoble Alpes

\section{Edición impresa}

ISBN: 978-2-37747-060-0

ISSN: $1639-6073$

\section{Referencia electrónica}

Sara Sánchez Calvo, «Pauline Roland. El compromiso de una vida militante », ILCEA [En línea],

33 | 2018, Publicado el 05 noviembre 2018, consultado el 25 abril 2019. URL : http://

journals.openedition.org/ilcea/5062 ; DOI : 10.4000/ilcea.5062

Este documento fue generado automáticamente el 25 abril 2019.

(c) ILCEA 


\title{
Pauline Roland. El compromiso de una vida militante
}

\author{
Pauline Roland. L'engagement d'une vie militante \\ Pauline Roland. The Commitment of a Militant Life
}

\section{Sara Sánchez Calvo}

1 El convulso y brillante siglo xIx llenó la historia de Francia de revueltas, revoluciones y luchas sociales. Gracias a la historiografía feminista y los estudios de género, sabemos desde hace unas décadas que las mujeres estuvieron presentes en ellas. Entre todas estas mujeres hay que resaltar un grupo, el de las autodenominadas proletarias sansimonianas, que jugaron un importante papel en diferentes campos reivindicativos durante las décadas de 1830 y 1840. Su carácter socialista les situaba del lado de «la clase más numerosa». Desde ahí dieron la batalla por los derechos de los trabajadores. Pero, por otra parte, su identidad femenina y, sobre todo, su conciencia de la opresión que sufrían por ésta, las hizo pioneras de un feminismo avant la lettre. En este colectivo, plural y diverso, destacan los nombres de Eugénie Niboyet (1796-1883), Jeanne Deroin (1805-1894), Claire Démar (1799-1833), Désirée Véret, también conocida como Désirée Gay (1810-1891), Suzanne Voilquin (1801-1877) y Pauline Roland (1805-1852).

2 En esta última se centrará el presente artículo, intentando analizar su más que destacable compromiso político y social, el cual determinará las decisiones más importantes de su vida y le conducirá a una muerte precoz. Su fallecimiento quizás pudo ser evitado, pero a costa de renunciar a sus ideales. Un precio muy alto, que no consintió en pagar. La escritora Benoîte Groult, en la biografía que le dedicó, Pauline Roland ou comment la liberté vint aux femmes, mencionó que observaba en ella un aparente deseo de martirio (Groult, 1991). Pese a ser solo una idea esbozada, nos sirve como punto de partida para revisar la vida personal y la militancia política de Roland desde este prisma. La figura del mártir, persona que sufre una persecución y una muerte cruel en defensa de sus creencias o de su religión, tiene una base cultural cristiana estrechamente relacionada con las ideas del propio Saint-Simon ${ }^{1}$, y, por tanto, con las convicciones de Roland. Pero si nos alejamos de conceptos religiosos y nos centramos en analizar su trayectoria militante, también encontraremos en ella un ejemplo de coherencia. Sin tratar de desmerecer a algunos de 
sus compañeros de lucha, que, por distintos motivos, abandonaron sus ideas revolucionarias o las moldearon con el paso del tiempo, en Roland veremos una valentía y una capacidad de sacrificio realmente sobresalientes. También haremos especial énfasis en cómo trasladó a su vida personal los mandatos de la doctrina sansimoniana referidos a la vida en pareja, al sexo y a la maternidad, con los que demostrará ser una alumna aventajada de esta escuela y una mujer adelantada a su tiempo. Para analizar todas estas cuestiones, recurriremos a sus propias palabras que, a través de extractos de su correspondencia, han sido recogidas en distintas obras. Y uniéndolas a lo que conocemos de su biografía, las pondremos en relación con los acontecimientos históricos que le tocó vivir.

3 Nacida en Falaise en 1805, Pauline Roland tuvo una cierta ventaja de partida sobre algunas de sus compañeras de lucha, ya que, gracias al trabajo de su madre como directora de la oficina de correos de la región, pudo recibir una buena educación. Precisamente gracias a su formación conocerá el sansimonismo, ya que su maestro, Desprez, era un ferviente seguidor de esta recién nacida corriente socialista ${ }^{2}$. Tras un tiempo de relación epistolar con la «familia» sansimoniana, en especial con Aglaé SaintHilaire $^{3}$, su primera guía espiritual, decide trasladarse a París y embarcarse de lleno en la cruzada de esta nueva doctrina política. El sansimonismo se encontraba en su momento de apogeo al calor del clima aún revolucionario que habían sembrado las Tres Gloriosas. Roland llega a París en 1832, un momento de especial interés en la historia de la lucha por la emancipación femenina. La llamada en ese momento "cuestión de la mujer», era un tema central en el sansimonismo desde 1829 , lo que le convertía en la primera doctrina política en dirigirse directamente a las mujeres (Riot-Sarcey, 2008). Y en 1831, un año antes de la llegada de Pauline, esta cuestión había sido el detonante del cisma que desvinculó del grupo al Padre Bazard y sus seguidores, dejando a Enfantin como único líder, con el camino libre así para desarrollar sus ideas y convertir, como quería, la escuela sansimoniana en Iglesia. Como responsable de la nueva ley moral que regirá la comunidad, Enfantin había declarado que era necesario superar la fidelidad impuesta por el matrimonio, si realmente se quería lograr la emancipación femenina. La inviolabilidad del matrimonio había sido un grave error del cristianismo, que negaba así los instintos humanos básicos de constancia y movilidad, y que traía como consecuencia el adulterio y la prostitución, problemas ambos de gran alcance en la sociedad de la época. Esta movilidad, entendida como un deseo de cambio de la pareja sexual, debía respetarse (Charléty, 1969).

Para Enfantin su propuesta de parejas progresivas significaba una verdadera rehabilitación de la carne, de la armonía universal entre los principios de movilidad y constancia. La promiscuidad y el libertinaje se controlarían desde la pareja sacerdotal que conocería el alma de cada pareja [...]. Buscar "uniones progresivas» es el objetivo. Esta teoría se propone fundamentar las nuevas relaciones entre los sexos como relaciones no jerárquicas (Campillo, 1992).

4 En la juventud de Roland, la rectitud moral y el sentimiento religioso, le apartaron de cualquier tentación que pudiera considerarse «libertina». La relación platónica que vivió durante años con Desprez, su joven y casado maestro, así lo atestigua. Sin embargo, el estudio y la interiorización de la doctrina sansimoniana, con respecto al cuerpo y la sexualidad, operarán un gran cambio en sus posicionamientos al respecto. Con la ley moral declarada por el Padre, Roland se replanteará su forma de relacionarse con el sexo opuesto. Este no será un caso particular, las sansimonianas se verán todas afectadas por estos nuevos posicionamientos, ya sea para aceptarlos, y ponerlos en práctica en mayor o menor medida, o para condenarlos. Por un proceso de revolución interna similar al de 
Roland pasará también Suzanne Voilquin, una de sus amigas y compañeras. Voilquin, que se dedicó al apostolado sansimoniano de 1830 a 1838, recoge en sus memorias cómo pasó de ser una joven tímida y temerosa, preocupada por el que dirán, a pensar, sentir y amar de una forma libre. También ambas mujeres compartirán al responsable directo de su «resurrección moral», Charles Lambert (Voilquin, 1863). Lambert era el responsable en ese momento de la enseñanza teórica y del desarrollo teológico dentro de la Familia, y fue el encargado por Enfantin para ser el director de conciencia de Roland. Él despertará en ella sentimientos llenos de una "exaltación mística», mientras le enseñaba la teoría de la inseparable asociación de mente y cuerpo. Pero de nuevo, era una relación únicamente platónica. Roland se había mantenido virgen, por decisión propia, hasta los veintiocho años y, también por decisión propia y sin casarse, iba a dejar de serlo. Y fue ella quien eligió como pareja para dar ese paso a Adolphe Guéroult, joven compañero sansimoniano cinco años menor que ella, a quien conoció precisamente a través de Lambert. Más allá de lo biográfico, lo más destacable como hecho político, fue el enfoque «doctrinal» que ella quiso dar a esta relación. Creía que la sexualidad, en este caso su sexualidad, podía ponerse al servicio del adoctrinamiento ideológico sansimoniano. Y así lo puso en práctica con Guéroult, con quien experimentó la unión completa que preconizaban, un amor que unía el cuerpo y el espíritu. Para los sansimonianos las uniones de hombre y mujer deberían ser un progreso tanto personal como social (Charléty, 1969). Liberada ya de los prejuicios que le aportaban los antiguos dogmas cristianos, Roland comenzó a vivir libremente su sexualidad, de la que disfrutaba en un entorno en el que sus compañeros la entendían de la misma manera. Una liberación personal pero, a la vez, una utilización autoimpuesta de su cuerpo por la causa social: «Chez Pauline la chair parlera haut et librement, mais jamais plus fort que le coeur et elle ne s'offrira qu'à des hommes qu'elle veut gagner à sa religion ou sauver du désespoir, incarnant en somme une sorte de prostitution sacrée» (Groult, 1991).

5 El siguiente hito del completo compromiso militante de Pauline Roland vendría poco después, con su embarazo. De nuevo aquí, volvió a mostrarse como la alumna aventajada del sansimonismo llevando a la práctica y hasta las últimas consecuencias los postulados del Padre. Este había declarado que la responsable de poner los límites a la unión sagrada de cuerpos sería la mujer, la cual también tendría el derecho de mantener en secreto o no la identidad del padre en caso de descendencia (Charléty, 1969). Las propias palabras de Pauline, en su correspondencia con Aglaé Saint-Hilaire, nos muestran sus dudas y, a la vez, su determinación sobre este tema:

Mère, vous le savez, ma vie entière est en jeu. Je suis entrée dans une route difficile et déjà les cailloux ont écorché mes pieds. N'importe, j'irai jusqu'au bout. Priez Dieu pour moi [...] Je désire être mère... mais je me suis sévèrement interrogée à ce sujet. Je me suis demandé si, dans l'état de maladie qu'entraîne toujours la grossesse, je serais assez forte pour ne pas demander à un homme de donner aux yeux du monde un nom à l'enfant dont il sera le père devant Dieu. Je me suis demandé aussi si j'avais le droit de donner le jour à un être rejeté par la société à cause de sa naissance. Les deux questions sont résolues affirmativement [...] Je serai fière de ma maternité et mon enfant sera fier de sa naissance (citado en Groult, 1991).

6 La decisión de ser madre soltera, de ser ella la única familia de sus hijos ${ }^{4} \mathrm{y}$ de que estos no lleven el apellido paterno, debería haber sido aplaudida por la familia sansimoniana, ya que ponía en práctica su teoría. Sin embargo, Roland no encontró el apoyo deseado, le criticaron ferozmente y le dieron de lado, incluso la propia Aglaé Saint-Hilaire, quien era su confidente y a quien consideraba su amiga ${ }^{5}$. Esta situación no mejorará, cuando poco 
después Roland comenzó una relación con Jean-François Aicard, con quien tendrá otros dos hijos 6 .

7 La siguiente etapa importante en su vida tuvo lugar unos años después, convertida en seguidora y amiga de Pierre Leroux, otro antiguo sansimoniano. Leroux (1797-1871), editor y filósofo socialista, fue de los pocos aliados políticos con los que pudieron contar las mujeres en sus reivindicaciones de derechos durante la Segunda República (Primi, 2010; Riot-Sarcey, 1994). Antes de eso, en 1843, abrió una imprenta y organizó un falansterio en Boussac (Creuse), en el que empezó a vivir con su familia, amigos y discípulos. La comunidad estaba basada en un ideario socialista y ecologista avant la lettre. Roland se trasladó allí junto a sus hijos y rápidamente comenzó a trabajar en la escuela, que dirigirá desde el invierno de 1847 hasta el verano de 1848 (Primi, 2010: 88). Esta actividad la compaginará con otras, como la continuación de su trabajo como periodista, en esta ocasión, en L'Eclaireur de L'Indre. Ella definirá esta época como la más feliz de su vida. «Je suis heureuse, tout à fait heureuse du parti que j'ai pris. Je finirai mes jours dans l'association où je suis... je l'espère du moins. Là se mène la meilleure vie qu'il soit donné à des hommes de coeur de mener» (citado en Groult, 1991). Pero los acontecimientos políticos cambiaron ese feliz camino emprendido al estallar la revolución de 1848. Antes de su vuelta a París, viviendo aún en Boussac, Roland dio otro paso adelante en la historia de las mujeres: intentó votar en las elecciones municipales. Ante la negativa, por parte de los responsables de la administración a que pudiera votar, ella exigirá un proceso verbal, en el que quede constancia oficial de esta prohibición. Pese a su "fracaso», éste será uno de los primeros hitos en el camino del sufragismo francés (Primi, 2010).

Roland regresa a París y se encuentra a sus compañeras, las antiguas proletarias sansimonianas, de nuevo muy activas y trabajando juntas, lideradas por Niboyet, Deroin, Voilquin y Gay. Habían comenzado a publicar el periódico, socialista y político, La Voix des Femmes. Inmediatamente después, crearon una Asociación Fraternal con el mismo nombre, en la que la lucha por la educación pública de las mujeres sería el eje central. Organizando a un número creciente de mujeres, multiplicaron sus proyectos sociales $\mathrm{y}$ sus campos de actuación: clubs de debate, creación de bibliotecas y de casas comunitarias, búsqueda de empleo a mujeres necesitadas, etc. (Adler, 1979).

Con el paso de los meses, debido a la sucesión de acontecimientos ${ }^{7}$ y tras varias convocatorias electorales, la Segunda República, que había nacido llena de promesas sociales, fue tornándose en conservadora y reaccionaria. Sin embargo, la ciudadanía de izquierdas, siguió organizándose intentando esquivar la persecución política. De entre los múltiples campos de activismo posibles, Roland centrará sus esfuerzos en la formación y desarrollo del asociacionismo. El 6 de febrero del 1849, se publica en el periódico Le Peuple una convocatoria para crear una asociación de profesores. En la reunión fundacional, la intervención de Roland, que acudirá junto a Jeanne Deroin, tendrá un marcado carácter socialista y será decisiva para la formación y la ideología de la nueva organización (Lefrançais, 2013) ${ }^{8}$. Unos meses después, queriendo dar un paso más en la organización de la clase obrera, pusieron en marcha la creación de una Unión de Asociaciones. Consiguieron contar con representación de 104 asociaciones profesionales. A la reunión fundacional, que tuvo lugar el 5 de octubre de 1849, Roland acudió como delegada de la Asociación fraternal de profesores y salió como miembro de la dirección elegida (Primi, 2010). Aunque los organizadores intentaron enmascarar el carácter político de esta federación para evitar la represión, resultó imposible: el 29 de mayo de 1850 una intervención policial se saldó con 47 detenidos, entre ellos Jeanne Deroin y Pauline 
Roland, calificada como comunista-socialista. Tras un proceso judicial que duró tres días, ambas serán condenadas a seis meses de prisión (Riot-Sarcey, 1994) ${ }^{9}$. Roland entra en la cárcel el 2 de enero de $1851^{10}$. Allí, su principal preocupación es el bienestar de sus hijos. Solicitará que puedan visitarla, pero no se lo permitirán. Tras unos primeros días de adaptación especialmente duros, comienza a ganarse el respeto de las presas comunes y de las prostitutas, a las que ayudará en todo lo que pueda. Comparte celda con Deroin, y ambas, irreductibles, continuarán desde allí con su actividad militante gracias a la correspondencia (Groult, 1991).

Pauline Roland sale de la cárcel a principios de julio, pero rápidamente, debido de nuevo a los acontecimientos históricos, su vida volverá a bascular. El 2 de diciembre de 1851, nada más comenzar el golpe de Estado de Napoleón III, sus amigos cercanos empiezan a ser encarcelados. Ya en esa misma noche serán arrestadas casi 80 personas. El pueblo revolucionario de París, que había sido masacrado en junio de 1848, no se levantó masivamente. El golpe atacaba a una Asamblea impopular y considerada reaccionaria. Aun así, se organizaron revueltas y se levantaron decenas de barricadas en el centro y este de la ciudad, que, bajo el ataque de las tropas militares, se saldaron con cientos de muertos. Más de 26000 personas son arrestadas por todo el país (Anceau, 2009). Y así, de nuevo, la sombra de la prisión se cierne sobre Roland. Sin embargo, se negará a esconderse o a exiliarse. Jeanne Deroin, ya se encontraba exiliada con sus hijos en Londres, como muchos otros compañeros. Solo en los tres primeros meses desde el golpe de Estado, llegaron a Inglaterra más de 4500 proscritos. Con gran diferencia, este fue el destino más común entre los obligados a huir, seguido de Bruselas (Aprile, 2010). Pero ella decidió quedarse:

Je ne crains nullement d'être compromise...j'attends mon sort. Mais quel qu'il soit, je l'aurai encouru en agissant en conformité avec mes principes. J'ai fait tout ce qui a été en moi pour maintenir le droit. Je le ferai toujours. Ma vie et celles de mes enfants sont dévouées au salut de la république. Je ne marchanderai jamais sur le prix dont sera payé mon salut. Et je ne l'achèterai pas au prix d'une déviation de principe (citado en Adler, 1979).

11 Será detenida en su casa el 6 de febrero de 1852, bajo las acusaciones de: haber participado en la insurrección del 2 de diciembre, ser miembro de sociedades secretas y publicar carteles llamando al pueblo a la resistencia al golpe (Groult, 1991). El nuevo gobierno creó una estructura legal, las comisiones mixtas, para «organizar» la represión. Los historiadores coinciden en la falta de garantías de la que adolecieron estos procesos judiciales: «À partir de début février, des commissions mixtes [...] condamnèrent à huis clos des milliers de personnes à la résidence surveillée, à l'exil ou à la déportation, sans entendre ni les inculpés, ni les témoins» (Anceau, 2009). "L'arbitraire le plus total avait régné dans cette épuration. On pouvait être condamné sans avoir bougé» (Cazals, 1999). En esta situación fue en la que se encontró Roland. Ella negó la acusación de haber participado activamente en las revueltas en contra del golpe de Estado y aportó una coartada en la que figuraban amigos a los que había ido a visitar ese día. Sin embargo, conservando su honestidad y valentía habitual, declaró al jurado: «Activement je n'ai pris aucune part à l'insurrection, mais dans mon cœur j'y ai pris une part active» (citado en Adler, 1979). También reconoció con tranquilidad, que era miembro de la Asociación fraternal de profesores, y que realizaba, y seguiría realizando, propaganda socialista, actividad que no consideraba peligrosa. Tras el proceso, fue condenada finalmente por tres delitos considerados probados: participar en loterías solidarias en apoyo a las familias de los detenidos, haber sido parte de los clubs de mujeres, y ser una peligrosa propagandista socialista. La pena que se impuso fue la deportación a Argelia (Groult, 1991). Como recoge Sylvie Aprile en su libro Le siècle des 
exilés, los represaliados del golpe de Estado podían ser condenados a diferentes penas: puesta en vigilancia, cárcel, alejamiento temporal, expulsión o deportación ${ }^{11}$, que era la peor de todas:

La transportation est la peine la plus dure et la plus élevée dans la gradation des condamnations. Elle est réservée "aux individus convaincus d'avoir pris part aux insurrections récentes" et créée afin de "rendre la peine des travaux forcés plus efficace, moins dispendieuse et en même temps plus humaine, en l'utilisant au progrès de la colonisation française ». Elle doit, selon les termes de l'époque, permettre "l'amendement du coupable par le travail de la terre» (Aprile, 2010).

12 De los cerca de veinte mil franceses que fueron condenados por las comisiones mixtas, 9820 fueron condenados a la deportación a Argelia, en mayor medida, o a Cayena en una cifra mucho menor. Dentro de la deportación a la colonia norteafricana había dos categorías: Argelia +, que consistía en la residencia forzada, y Argelia-, en la que se permitía la residencia libre. Roland fue condenada a la primera, la opción más dura. Precisamente otro condenado a la deportación, pero este en 1849, el escritor y periodista Charles Ribeyrolles, recogió en su obra Les Bagnes d'Afrique. Histoire de la transportation de décembre (1853), parte de la correspondencia de Roland, haciéndonos más accesibles sus propias palabras en esos meses decisivos. Desde el inicio de su condena, y pese a la insistencia de parte de sus amigos, Roland siempre se mantuvo firme en su decisión de no pedir ninguna medida de gracia, no se doblegaría ante Napoleón III. Nada más enterarse de que va a ser deportada, vemos clara su determinación, en una carta escrita desde la prisión de Saint-Lazare y fechada el 8 de marzo de 1852: "Je suis condamnée à la transportation, - l'Algérie, je crois; et, comme, je suis bien résolue à ne rien demander ou laisser demander, il est très probable que le jugement recevra son exécution». Continúa la misiva manifestando su fortaleza, «je ne suis nullement abattue par le coup qui me frappe», para seguidamente manifestar su constante preocupación por el bienestar de sus hijos, decidida a escribir al ministro de la Guerra para pedirle que puedan acompañarle en su destierro (Ribeyrolles, 1853). De nuevo, como para su estancia en la cárcel, la petición de tener a sus hijos con ella le será denegada. Pero esta vez, más adelante, al ver sus condiciones de vida en Argelia se alegrará de que haya sido así. Sobre sus últimos días en prisión, destaca el duro retrato que hace de las monjas que gestionaban Saint-Lazare y que por tanto eran las responsables del estado de las reclusas:

Les religieuses, leur supérieure en tête, viennent régler de petits comptes de travail fait pour la prison par quelques-unes de nous, et l'ouvrage est si minutieusement visité, si scrupuleusement examiné, qu'on retranche à peu près moitié des salaires à des femmes sans ressources! Du reste, pour rendre justice à ces saintes en Dieu, nous devons dire que pas un mot de consolation et pas un mot de sympathie ne leur échappa vis-à-vis des pauvres sacrifiées, pas un verre d'eau ne fut offert à celles qui vont, au milieu de mille dangers, prendre le chemin de l'exil : ceci sans doute eût été grave infraction à cette règle de fer dont le premier article semble être: Tu n'aimeras pas (citado en Ribeyrolles, 1853).

13 Al llegar a Argelia, primero es instalada en el fuerte Saint-Grégoire, donde empieza a ver las condiciones de vida que le esperan: falta de descanso, malas camas y peor alimentación. Rápidamente la vuelven a embarcar, camino a Argel.

En este viaje, da una nueva muestra de su interiorización de la solidaridad que reclamaba y de su gran capacidad de sacrificio: le ofrecen un camarote de oficial, haciéndole un favor excepcional, y ella lo rechaza negándose a disfrutar de un privilegio que sus compañeras de deportación no podían compartir. Es trasladada, junto a sus compañeras, al convento del Buen Pastor en El-Biar, donde de nuevo se encontrará bajo tutela religiosa. Allí la alimentación será igual de mala, pero el alojamiento será aún peor, 
estando quince mujeres encerradas en una misma habitación. Declarará que vivía un verdadero infierno, pues a todo ello, tendrá que sumar la persecución moral que sufrían, bajo «las formas hipócritas de la misericordia cristiana». Las religiosas conseguirán «convertir» a algunas de sus compañeras, pero con ella no serán capaces de «devolverla al redil». Se enfrentará a las monjas, defendiendo su religión con su innata capacidad de argumentación y oratoria:

La matière est divine comme l'esprit, ose-t-elle dire à ces chastes personnes. Croyez-vous que Dieu s'intéresse à vos prières insignifiantes, à vos mortifications, à vos coiffures, à vos habits, au poisson que vous mangez certains jours de l'année? Nous réhabilitons la chair, nous avons une religion d'action: Dieu préfère nous voir améliorer l'état économique, social, spirituel du monde (citado en Groult, 1991).

15 Así, será ella la que acabe con la paciencia de las religiosas. La superiora escribirá al gobernador de Argelia para suplicarle que las libren de esa mujer indomable, a la cual además consideran una nefasta influencia para las otras mujeres. Deciden trasladarla a Sétif, en régimen de residencia libre, comunicándoselo de esta manera: «Attendu que vous êtes une personne fort dangereuse, réunissant en elle l'attrait de la première madame Roland, et les fureures de Théroigne de Méricourt, nous vous envoyons à Sétif, dans un trou il vous sera impossible d'agir !» (citado en Ribeyrolles, 1853). Efectivamente, la vida que llevará allí será muy dura, trabajando como lavandera y cocinera, y aun así llena de privaciones y con la preocupación constante por el bienestar de sus hijos ${ }^{12}$.

16 En abril de 1852, se ponen en marcha los procesos de petición de indulto para los condenados por levantarse contra Napoleón III (Aprile, 2010). El perdón sería concedido directamente por el presidente de Francia, a quien había que pedirle clemencia. Esta sería la única opción de Roland para regresar a su país rápidamente. En una carta fechada el 14 de octubre encontramos su opinión:

Il y a un peu plus de quinze jours, nous fûmes prévenus, par une circulaire émanant du gouverneur-général, que ceux de nous qui voulaient obtenir soit leur retour en France, soit l'internement définitif, soit toute autre commutation de peine devaient, dans les quarantehuit heures, produire une demande en grâce adressée directement à Monseigneur le président de la République. La formule était indiquée, et au plus, pouvait-on lui faire subir certaines modifications littéraires. Je n'ai produit et j'ajoute, je ne produirai aucune demande de ce genre: ma conscience s'y refuse (citado en Ribeyrolles, 1853).

De nuevo vemos como antepone su conciencia por encima de todo. Por encima de encontrarse con sus hijos, por encima de su propia salud, que ya venía resintiéndose debido a las condiciones de vida que sufría. De nuevo su sacrificio por la causa. El exilio tampoco será para ella una opción ${ }^{13}$. No lo fue ante la fuerte y real amenaza de ser encarcelada por segunda vez, ni lo será ante su posible vuelta a Francia tras su deportación. Declaró que prefería soportarlo todo, miseria, prisión e incluso la muerte, antes que el exilio que la separaría de su querida tierra (Groult, 1991). Aunque ella se negó a claudicar ante Napoleón III, en París, la intermediación de sus amigos George Sand y Pierre-Jean de Béranger y de su propio hijo Jean, estaba dando sus frutos: se la concedió la libertad anticipada en noviembre de 1852. Embarcó hacia Marsella con la salud ya mermada y las condiciones de su viaje de vuelta a Francia, que serán especialmente duras, terminarán de agravar su estado: «Je frissonnerai toute ma vie en songeant à ce que j'ai enduré sur ce pont où, malade de la mer comme je ne l'avais jamais été, je suis restée vingt-quatre heures couchée au milieu de l'eau sans qu'aucun être humain ne m'offrit du secours» (citado en Adler, 1979). Así, llegando a Francia muy enferma, fallecerá poco después en Lyon el 16 de diciembre de 1852, a los 47 años. 
hemos podido observar, la resistencia política y personal que demostró, hacen de ella un caso excepcional de mujer revolucionaria. Recuperando la idea de la figura de la mártir, que citábamos al inicio, no parece que su martirio fuera impostado, sino totalmente auténtico y alejado de la búsqueda de reconocimiento público. Fue fruto de una creencia absoluta en sus convicciones y en la puesta en práctica de lo que consideraba sus derechos, como mujer y como trabajadora, estuvieran estos o no reconocidos por la legalidad vigente en su época. En los momentos más duros de su intensa biografía, no hubiera sido reprochable que diera un paso atrás o que incluso claudicara, como hicieron muchos de sus coetáneos, sin embargo, no fue así. Siguió el camino que su militancia le marcó a pesar de su dureza. De esta manera Pauline Roland, la luchadora por los derechos de las mujeres, la gran defensora de la asociación universal, la pionera que llegó a plantear un gobierno directo de los trabajadores (Riot-Sarcey, 2016), había vivido y muerto siendo perfectamente coherente a sus ideas. Sin caer en contradicciones en las que cayeron algunas de sus compañeras respecto al matrimonio o la maternidad. Con sus posicionamientos morales y religiosos intactos. Con el socialismo y la fraternidad por bandera. Generosa y militante hasta el final.

\section{BIBLIOGRAFÍA}

ADLER Laure (1979), À l'aube du féminisme : les premières journalistes (1830-1850), Paris: Payot.

ANCEAU Éric (2009), «Le coup d'État du 2 décembre 1851 ou la chronique de deux morts annoncées et l'avènement d'un grand principe ", Parlement [s], Revue d'histoire politique, 2/2009 (12), 24-42.

APRILE Sylvie (2010), Le siècle des exilés. Bannis et proscrits de 1789 à la Commune, Paris: CNRS Éditions. CAMPILlo Neus (1992), «Las Sansimonianas: Un grupo feminista paradigmático», C. Amorós (coord.), Feminismo e Ilustración 1988-1992, Madrid: Instituto de Investigaciones Feministas, 313-325.

CAZALS Rémy (1999), « Les proscrits de 1852 », MIREHC Mémoires Identités Représentations Histoire comparative de l'Europe (3), 24-32.

CHARLÉTY Sébastien (1969), Historia del sansimonismo, Madrid: Alianza Editorial (versión original publicada en 1931 bajo el título Histoire du saint-simonisme. 1825-1864, Paris: Paul Hartmann Éditeur).

DÉMAR Claire (1976), Textes sur l'affranchissement des femmes (1832-1833), Paris: Payot.

GROULT Benoîte (1991), Pauline Roland ou comment la liberté vint aux femmes, Paris: Laffont.

LEFRANÇAIS Gustave (2013), Souvenirs d'un révolutionnaire, Paris: La fabrique éditions.

Pelosse Valentin (1976), « Symbolique groupale et idéologie féministe saint-simoniennes », C. Démar (dir.), Textes sur l'affranchissement des femmes (1832-33), Paris: Payot, 167-226.

PRIMI Alice (2010), Femmes de progrès. Françaises et allemandes engagées dans leur siècle, 1848-1870, Rennes: Presses universitaire de Rennes. 
RiBeyrolles Charles (1853), Les Bagnes d'Afrique. Histoire de la transportation de décembre, Londres: Jeffs.

RIOT-SARCEY Michèle (1994), La démocratie à l'épreuve des femmes. Trois figures critiques du pouvoir, 1830-1848, Paris: Albin Michel.

RIOT-SARCEY Michèle (2008), Histoire du féminisme, Paris: La Découverte.

RIOT-SARCEY Michèle (2016), Le procès de la liberté, Paris: La Découverte.

SAINT-Simon Conde de (2004), Nuevo Cristianismo, Buenos Aires: Editorial Biblos.

VEAUVY Christiane (2011), « Les saint-simoniennes en Égypte. Analyse critique d'un modèle

d'émancipation », Lectora (17), 221-239.

VoILQUIN Suzanne (1863), Souvenirs d'une fille du peuple, ou La Saint-Simonienne en Égypte, 1834-1836,

París: E. Sauzet Librairie.

\section{NOTAS}

1. De hecho, él pretendió crear un Nuevo Cristianismo, título de su último trabajo, aparecido en 1825. Esta obra se pude considerar póstuma ya que se publicó solamente unos meses antes del fallecimiento del maestro. En ella, Claude Henri de Rouvroy, Conde de Saint-Simon (1760-1825), postulaba por crear una nueva religión, adaptada a una sociedad moderna que comenzaba a industrializarse, y que recogiera los ideales del cristianismo primitivo. Dentro de los tres pilares de la divisa republicana, debería desarrollarse especialmente la fraternidad, derivando de ella el concepto de asociación. Este planteamiento básico del sansimonismo queda claro desde el inició de la obra que comienza con la célebre epístola a los romanos de San Pablo: amarás a tu prójimo como a ti mismo (Saint-Simon, 2004).

2. Para conocer estos y otros aspectos biográfícos en profundidad ver: Pauline Roland ou comment la liberté vint aux femmes, de Benoîte Groult (Groult, 1991).

3. Aglaé Saint-Hilaire, amiga personal del líder sansimoniano, el Padre Prosper Enfantin, era una de las pocas mujeres cercanas a la cima jerárquica de la organización. Junto con Claire Bazard (esposa del otro Padre, Armand Bazard) y Cécile Fournel, liderarían al sector más conservador de las discípulas femeninas, las conocidas como «damas de la doctrina» o «damas con sombrero»; frente a las «proletarias sansimonianas», entre las que se encontraría Pauline Roland. Para ampliar este tema ver el capítulo primero de À l'aube du féminisme: les premières journalistes (1830-1850), de Laure Adler (Adler, 1979).

4. Roland tendrá tres hijos: Jean, fruto de esta primera relación con Guéroult, e Irma y Moïse, de su relación de doce años con Jean-François Aicard. Todos nacidos fuera del matrimonio y que llevarán su apellido.

5. Otro ejemplo de esta «doble moral» y falta de apoyo entre compañeros, lo encontramos en el caso de Claire Démar. Con un ideario considerado radical por su propio entorno, seguramente por lo avanzado de su pensamiento feminista, publicó en 1833 Appel d'une femme au peuple sur l'affranchissement de la femme. En él hacía una dura crítica a la falta de derechos de las mujeres y calificaba el matrimonio de prostitución legal. La respuesta que encontró fue el rechazo y la soledad: «Sa brochure ne fut pas lue, encore moins discutée et personne dans la famille ne l'aida pour l'imprimer» (Adler, 1979). Pese a todo, escribirá otra obra adelantada a su tiempo, Ma Loi d'avenir, que será publicada de forma póstuma por Voilquin. Démar no soportará la presión social que le condenaba al ostracismo y no le permitía vivir su sexualidad libremente. Se suicidó a los treinta y tres años junto a Perret des Issarts, compañero sansimoniano diez años más joven que ella. Tras su sonada muerte se la considerará emblema de «La femme libre», cargando esta expresión de 
connotaciones negativas que llegarán hasta nuestros días (Veauvy, 2011). Para más información ver la reedición de sus textos realizada por Valentin Pelosse (Démar, 1976).

6. Para sacar a sus hijos adelante de forma independiente, en los siguientes años Roland se centrará en la escritura. Entre otros encargos, trabajará en prensa colaborando con varios periódicos, escribiendo Histoire de France des origines à nos jours (1835), Histoire d'Angleterre à l'usage des enfants (1838) e Histoire d'Écosse et d'Irlande (1844), y redactará artículos de geografía e historia para l'Encyclopédie nouvelle de Pierre Leroux.

7. Especialmente a la dramática represión obrera de las Jornadas revolucionarias de junio de 1848.

8. El programa educativo que publicó la asociación se puede consultar en la página web de la BnF: Programme d'éducation / Association fraternelle des instituteurs, institutrices et professeurs socialistes [réd. par G. Lefrançais, P. Roland, Pérot], <http://catalogue.bnf.fr/ark:/12148/cb34031667q>.

9. Para más información sobre este tema ver Souvenirs d'un révolutionnaire, autobiografía de Gustave Lefrançais, cofundador junto a Roland de Asociación de profesores (Lefrançais, 2013).

10. Cumplirán la pena en la prisión de Saint-Lazare, situada en el distrito 10 de París. Este edificio emblemático hacía labores de prisión desde el siglo xviI, y contó con una larga lista de revolucionarios entre sus muros. Pero a finales del xviı pasa a ser exclusivamente una cárcel de mujeres, jugando un importante papel en el control médico y el internamiento de prostitutas. Entre los miles de mujeres que fueron allí encerradas, destacan los nombres de la líder de la Comuna, Louise Michel, y de la célebre espía Mata Hari. La cárcel de Saint-Lazare fue cerrada en 1927.

11. La pena de deportación venía siendo habitual en Francia desde el siglo XVIII, estrechamente relacionada con la política colonialista y aplicada para crímenes contra la seguridad del Estado. La Segunda República al abolir la pena de muerte, sustituye ésta por la pena de deportación para crímenes políticos, a través de la Ley del 8 de junio de 1850. Sin embargo, los decretos de transportación de Napoleón III también incluirán a los criminales comunes condenados a trabajos forzados.

12. Para más información sobre esta época de su vida, ver Les Bagnes d'Afrique de Ribeyrolles, donde está recogida su correspondencia de esta época (Ribeyrolles, 1853). Esta obra se puede consultar en la página web de la BnF: <http://catalogue.bnf.fr/ark:/12148/cb31207797p>.

13. Algunos condenados de Napoleón III solicitaron conmutar la pena con el exilio (Aprile, 2010).

\section{RESÚMENES}

Este artículo analiza la biografía de Pauline Roland (Falaise, 1805 -Lyon, 1852), mujer revolucionaria vinculada a las nuevas ideas socialistas, poniendo el foco especialmente en su interiorización y puesta en práctica de los postulados sansimonianos referentes a la sexualidad, el matrimonio y la maternidad. Roland entregó su vida a su ideología política, en un sentido tanto literal como figurado, en pro de la causa mayor que defendía: la libertad de las mujeres y de los trabajadores. Podremos ver como su fuerte sentimiento de abnegación y su enorme capacidad de sacrificio, que rozaban el deseo de martirio, determinarán sus decisiones más importantes. Nos centraremos en algunos de los hitos de su militancia, relacionados con los pasajes más intensos de esta, principalmente la vinculación de su militancia con su vida sentimental, sus dos 
detenciones y encarcelamientos y su deportación a Argelia. Para analizar estos aspectos, nos basaremos en sus propias palabras, utilizando parte de su correspondencia recogida en varias obras, que serán el corpus principal de este trabajo. Al poner todos estos aspectos en relación con el momento histórico que vivió y con la experiencia de sus propias compañeras de lucha, cabrá preguntarse si Roland fue la alumna aventajada del sansimonismo, la «utópica ideal», para quien militancia política y vida fueron indisolubles, hasta las últimas consecuencias.

Cet article analyse la biographie de Pauline Roland (Falaise, 1805 -Lyon, 1852), femme révolutionnaire impliquée dans les nouvelles idées socialistes, en se focalisant tout particulièrement sur son intériorisation et sa mise en pratique des postulats saint-simoniens liés à la sexualité, le mariage et la maternité. Roland a sacrifié sa vie pour son idéologie politique, au sens propre comme au sens figuré, et principalement pour une cause : la liberté des femmes et des travailleurs. Nous verrons comment son fort sentiment d'abnégation et son énorme sens du sacrifice, qui frisait le désir de martyre, déterminèrent ses décisions les plus importantes. Nous nous concentrerons sur certains moments forts de son militantisme, en particulier sur les liens avec sa vie sentimentale, sur ses deux arrestations et peines de prison et sur sa déportation en Algérie. Pour analyser ces aspects, nous nous baserons sur ses propres mots, en utilisant une part de sa correspondance reprise dans quelques œuvres, qui sera le corpus principal de ce travail. En mettant tout cela en relation avec la période historique pendant laquelle elle a vécu et avec l'expérience de ses compagnes de lutte, il faudra se demander si Roland a été l'élève avantagée du saint-simonisme, si elle était «l'utopique idéale», pour qui militantisme politique et vie personnelle ont été indissociables jusqu'au bout.

This article analyses the biography of Pauline Roland (Falaise, 1805 - Lyon, 1852), a revolutionary woman linked to the new socialist ideas, paying special attention in her internalisation and implementation of the Saint-Simonian postulates about sexuality, marriage and maternity. Roland laid her life for her political ideology and for the greater cause she defended: the freedom of women and workers. In this article could be seen how her most important decisions in life will be determined by her strong sense of self-denial and her enormous capacity for sacrifice, closer to a desire for martyrdom. Some of her militancy milestones will be highlighted, especially those connected to her sentimental life, her two arrests and her imprisonment and deportation to Algeria. In order to analyse these aspects, her correspondence, collected in various works, will be used as the corpus of this study. Furthermore, all these aspects will be putted in relation with the historical moment in which she lived and the experience of her own companions in struggle. Then, one might wondered whether Roland was a privileged student of Saint-Simonianism, the "ideal utopian", for whom political militancy and life were linked even to the last consequences.

\section{ÍNDICE}

Mots-clés: saint-simonisme, féminisme, révolution de 1848, déportation, XIXe siècle Palabras claves: sansimonismo, feminismo, revolución de 1848, deportación, siglo XIX

Keywords: saint-Simonianism, feminism, revolution of 1848, deportation, 19th century

\section{AUTOR}

\section{SARA SÁNCHEZ CALVO}

Doctorante d'Études féministes de genre dans l'INSTIFEM, de l'Université Complutense de Madrid (UCM). Sa thèse traite de la vie et du travail politique de la socialiste et féministe, avant la lettre, 
Jeanne Deroin (1805-1894), sous la codirection de Christine Planté (Lyon 2).

sarasanchezphoto@gmail.com 